\title{
Detection and Study of Interleukin -21 Levels in Art Recipients
}

\author{
Manoj Kumar Meena ${ }^{1 *}$, V. G. Ramachandran ${ }^{1}$, Shukla Das ${ }^{1}$, Kuldeep Kumar² and Gargi Rai ${ }^{1}$ \\ ${ }^{1}$ Department of Microbiology, UCMS \& GTB Hospital, Delhi, India \\ ${ }^{2}$ Department of Medicine, UCMS \& GTB Hospital, Delhi, India
}

\begin{abstract}
Background: Interleukin-21 (IL-21) is a relatively new immune-enhancing, multifunctional and pleiotropic cytokine that plays an essential role in controlling chronic viral infections. It is a protein that in humans is encoded by IL-21 gene, mapped on chromosome 4 and $180 \mathrm{~kb}$ from IL-2 gene and the mRNA encoding the product is 616 nucleotides long. IL-21 is expressed in activated human CD4+ T cells but not in most other tissues. In addition, IL-21 expression is up-regulated by Th2 and Th17 subsets of T helper cells, as well as T follicular cells. Further IL-21 is expressed in NKT cells regulating the functions of these cells. IL-21 may be a critical factor in the control of persistent viral infections such as HIV.The intrinsic ability of IL-21 to promote the longevity of B cells should benchmark its role in sustained production of neutralizing antibodies by proliferating and differentiating B cells committed to cognate stimulating antigenic determinants. Nonetheless, immune response to identical or related antigenic insults are quite heterogeneous enlisting complex factors including ethnic and HLA elements in determining the final outcome. Present study aims to explore the levels of IL-21 in a select segment of ART recipients of East Delhi covered by NACP, Govt. of India.
\end{abstract}

Methods: Estimation of levels of IL-21 was done using ELISA test employing commercially available kit (QAYEE-BIO Kit for Interleukin-21). The method of ELISA used for the present study was sandwich ELISA.

Results: The mean levels of IL-21 in the study of 40 ART recipients were $1178.21 \pm 927.063$. There were no controls included in the study. The range of IL-21 were 150-6100. In one patient IL-21 levels was not detected.

Conclusion: This study attempts a clinical correlation with the levels of a cytokine which could help in a better understanding of the immunobiology of the disease. In the current study, the levels of IL-21 in samples of ART recipients were detected. In all ART patients the levels of Interleukin-21 were detected except one. Majority of patients showed moderate levels of IL-21. But 3 patients showed high levels of IL-21 $>2000 \mathrm{pg} / \mathrm{ml}$ who were not associated with opportunistic infections after 10 to 12 months of ART treatment. Therefore, further studies with a higher sample size may be required to arrive at a statistically significant correlation.

Keywords: IL-21; ART Recipient; HIV; CD-4 count; CRP; People Living with HIV/AIDS (PLHA)

\section{Introduction}

IL-21 may be a critical factor in the control of persistent viral infections such as HIV. HIV infection is characterized by a progressive qualitative and quantitative deficiency of CD4 T cells and broad immunological defects that include immune-suppression in concert with increased inflammation and immune activation. CD4 T cell depletion is evident in circulation as well as in lymphoid tissue. Since CD4 T cells are the main source of IL-21, there is considerable interest in determining whether and how HIV infection alters IL-21 production.

Since its discovery in 2000, several studies have demonstrated that IL-21, alone and/or in combination with other cytokines such as IL-2, IFN- $\alpha$ or IL-15, activates NK cells and enhance their proliferation. IL-21 is one of a group of cytokines including IL-2, IL-4, IL-7, IL-9 and IL15 whose receptors' complex share a common $\gamma$ chain $(\gamma \mathrm{c})$. Furthermore, plasma cells are the antibody secreting cells.
${ }^{[5]}$ The generation of these long-lived plasma cells depends on a series of highly orchestrated interactions between antigen-specific $\mathrm{CD} 4 \mathrm{~T}$ cells and $\mathrm{B}$ cells and the formation of germinal centres. IL-21 is a critical cytokine for the generation of virus-specific long-lived plasma cells. ${ }^{[6]}$

IL-21 receptor (IL-21R) is expressed on the surface of $\mathrm{T}, \mathrm{B}$ and NK cells. IL-21R is similar in structures to the receptors for other type I cytokines like IL-2R or IL-15 and requires dimerization with the common gamma chain $(\gamma c)$ in order to bind IL-21. When bound to IL-21, the IL21 receptor acts through the JAK/STAT pathway, utilizing Jak1 and Jak3 and STAT3 homodimer to activate its target genes. ${ }^{[1]}$

IL-21 is produced mainly by $\mathrm{CD} 4^{+} \mathrm{T}$ cells, which are also the main targets of HIV-1 and often depleted in HIV infected individuals. ${ }^{[2]}$

Unfolding the spectrum of activity of this cytokine has stimulated interest in the search for ways to harness it in 
strategies to prevent HIV infection as a vaccine adjuvant and as a therapeutic tool in acute and chronic phases of the disease in infected host. It is a unique cytokine that targets a wide range of immune cells thus offering an interesting perspective of its potential clinical utility. ${ }^{[2]}$

The intrinsic ability of IL-21 to promote the longevity of B cells should benchmark its role in sustained production of neutralizing antibodies by proliferating and differentiating B cells committed to cognate stimulating antigenic determinants. ${ }^{[4]}$ Nonetheless, immune response to identical or related antigenic insults are quite heterogeneous enlisting complex factors including ethnic and HLA elements in determining the final outcome. Present study aims to explore the levels of IL-21 in a select segment of ART recipients of East Delhi covered by NACP, Govt. of India.

\section{Materials and Methods}

This study was conducted in Departments of Microbiology and Medicine, University College of Medical Sciences and Guru Teg Bahadur Hospital, Delhi-110095 during November 2013 to April 2015.The 40 HIV reactive Patients of age more than 18 years, who were ART recipients for a period of 6 months to 1 year having a CD4 Count of $<350$ cells $/ \mu 1$ were enrolled as subjects in this study. ART recipients with SLE and other autoimmune diseases, HIV and TB coinfection and pregnant females were excluded from the study. This study was undertaken after written informed consent from patients and clearance from Institutional Ethical Committee of UCMS \& GTB Hospital, Delhi.The sample 3-5 $\mathrm{ml}$ of venous blood was collected from each patient under aseptic precautions. Sera were separated and stored at $-70^{\circ} \mathrm{C}$ for estimations of IL-21 levels using ELISA test employing commercially available kit (QAYEE-BIO Kit for Interleukin-21). Routine Investigations including Heamoglobin ( $\mathrm{Hb})$, Total Leucocyte Count (TLC), Differential Leucocyte Count (DLC), Thrombocyte count / platelet count, Erythrocyte Sedimentation Rate (ESR), Blood sugar estimation (RBS), $\mathrm{C}$ - reactive protein (CRP) were also included and recorded each patient.

\section{Statistical Analysis}

Data which obtained from ART clinic were studied as continuous variable data. For continuous variable data, two types of tests were used. Parametric and/or non-parametric tests. Pearson's correlation or Spearman correlation was applied between IL-21 and other clinical and laboratory parameters depending on normality of these parameters.

Spearman correlation was applied to correlate levels of IL21 with CD4 Count.

\section{Results:}

Fifteen patients of HIV on ART were between 25-30 years of age. The age distribution of study population is shown in Figure 1.

60 percent of patients enrolled in the study were males. Male-Female ratio in this study was 3:2 as shown in Figure 2.

In Table 1, the common mode of transmission amongst the ART recipients is shown.

The most common mode of transmission was heterosexual and seen in $30(75.56 \%)$ patients followed by homosexual transmission in $8(20 \%)$ of patients.

The CD4 cell count ranged from $76-348$ cells/ $\mu 1$ as shown in Table 2

\section{Levels of Interleukin-21 in the ART recipients were as follows:}

1. In 24 patients, serum levels of IL-21 less than $<1000$ $\mathrm{pg} / \mathrm{ml}$.

2. In 15 patients, serum levels of IL-21 more than $>1000$ $\mathrm{pg} / \mathrm{ml}$.

3. There was a single patient in which IL-21 level was not detected.

\begin{tabular}{|l|l|}
\hline IL-21 & Mean \pm SD \\
\hline IL-21 in 39 patients & $\begin{array}{l}1178.21 \pm 927.063 \\
(150-6100)^{*}\end{array}$ \\
\hline
\end{tabular}

In 1 patient IL-21 not detected *Range of IL-21

Table 1: Mode of transmission of HIV amongst patients.

\begin{tabular}{|l|c|}
\hline Mode of transmission & $\begin{array}{c}\text { PATIENTS } \\
\mathbf{n}=\mathbf{4 0}\end{array}$ \\
\hline Heterosexual & $30(75.56 \%)$ \\
\hline Homosexual & $8(20 \%)$ \\
\hline Infected needle / syringes & $1(2.23 \%)$ \\
\hline Blood transfusion & $1(2.23 \%)$ \\
\hline
\end{tabular}

Data has been described as No (\%) 
Table 2: The CD4 cell count ranged from 76-348 cells/ $\mu$.

\begin{tabular}{|l|c|}
\hline $\begin{array}{l}\text { CD4 Cell Count } \\
\text { (cells/ } \mu \mathrm{l})\end{array}$ & $\begin{array}{c}\text { mean } \pm \text { SD } \\
\text { (Range) }\end{array}$ \\
\hline 40 patients & $271.10 \pm 67.646$ \\
\end{tabular}

Table 3: Serum Levels of Interleukin-21 in patients enrolled in the study.

\begin{tabular}{|c|c|c|c|c|c|c|c|}
\hline S.NO. & IL-21* & $\begin{array}{l}\text { cd4 cell } \\
\text { count }\end{array}$ & CRP\$ & S.NO. & IL-21* & $\begin{array}{l}\text { CD4 Cell } \\
\text { Count }\end{array}$ & CRP \\
\hline 1 & 1100 & 338 & 4.8 & 21 & 150 & 136 & 26 \\
\hline 2 & 1050 & 212 & 6.5 & 22 & 750 & 190 & 21 \\
\hline 3 & 850 & 160 & 12 & 23 & 700 & 220 & 16 \\
\hline 4 & 800 & 152 & 9 & 24 & 1100 & 288 & 11.5 \\
\hline 5 & 1850 & 342 & 4.5 & 25 & 950 & 310 & 9 \\
\hline 6 & 1100 & 332 & 5 & 26 & 900 & 388 & 12 \\
\hline 7 & 1250 & 210 & 7 & 27 & 700 & 392 & 8.5 \\
\hline 8 & 1000 & 170 & 9 & 28 & 1100 & 318 & 10 \\
\hline 9 & 800 & 192 & 8.5 & 29 & 950 & 312 & 12.5 \\
\hline 10 & 900 & 210 & 6.5 & 30 & 850 & 180 & 21 \\
\hline 11 & 950 & 188 & 8 & 31 & 950 & 196 & 17 \\
\hline 12 & 1100 & 308 & 5.2 & 32 & 900 & 178 & 23 \\
\hline 13 & 900 & 280 & 7.5 & 33 & 950 & 224 & 11 \\
\hline 14 & 700 & 240 & 8 & 34 & 900 & 236 & 9 \\
\hline 15 & 2250 & 348 & 6.5 & 35 & 950 & 290 & 13.5 \\
\hline 16 & 1650 & 312 & 16 & 36 & $\mathrm{Nd}$ & 126 & 24 \\
\hline 17 & 6100 & 346 & 7 & 37 & 2800 & 340 & 9 \\
\hline 18 & 1550 & 296 & 9.5 & 38 & 850 & 318 & 11.5 \\
\hline 19 & 1100 & 248 & 11 & 39 & 750 & 362 & 8.5 \\
\hline 20 & 1150 & 290 & 19 & 40 & 600 & 280 & 16.5 \\
\hline
\end{tabular}

$\mathrm{Nd}-$ not Detectable $* \mathrm{pg} / \mathrm{ml} \quad$ \# Cell/ $\mathrm{ul} \$ \mathrm{mg} / \mathrm{dl}$

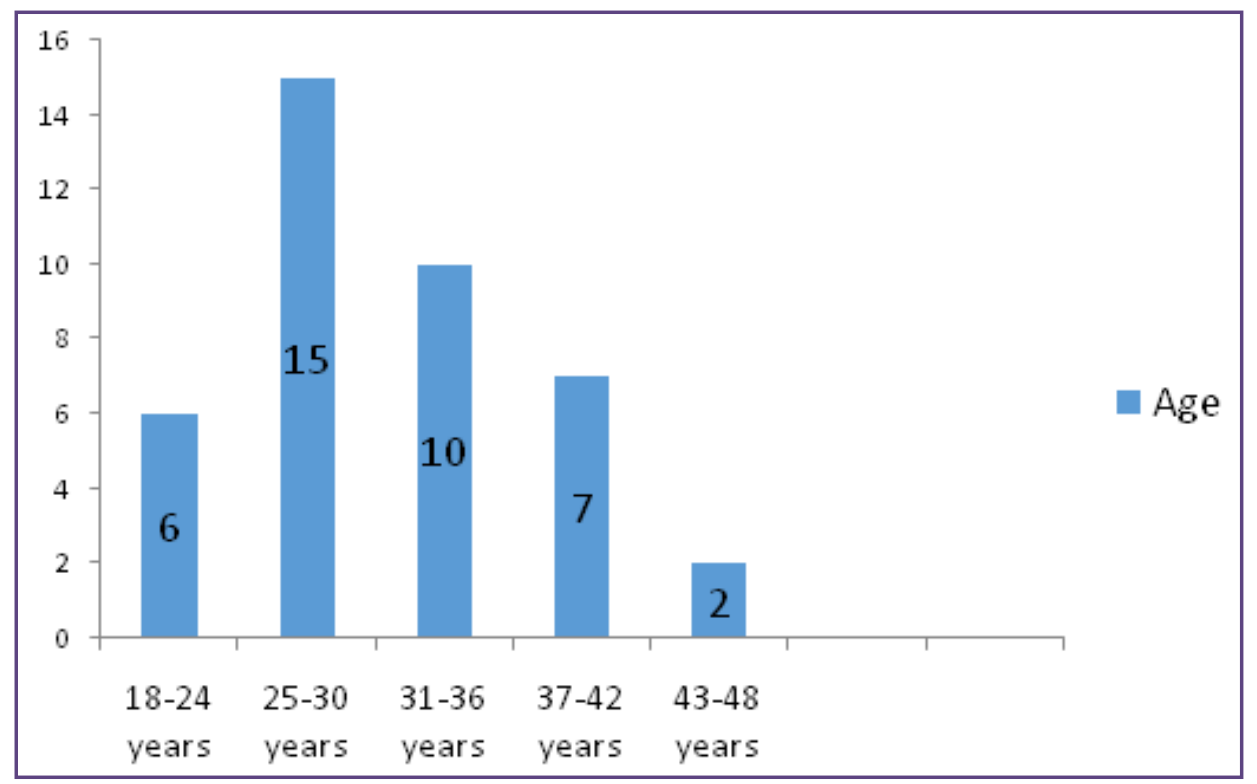

Fig. 1: Age Distribution of ART patients in the study. 


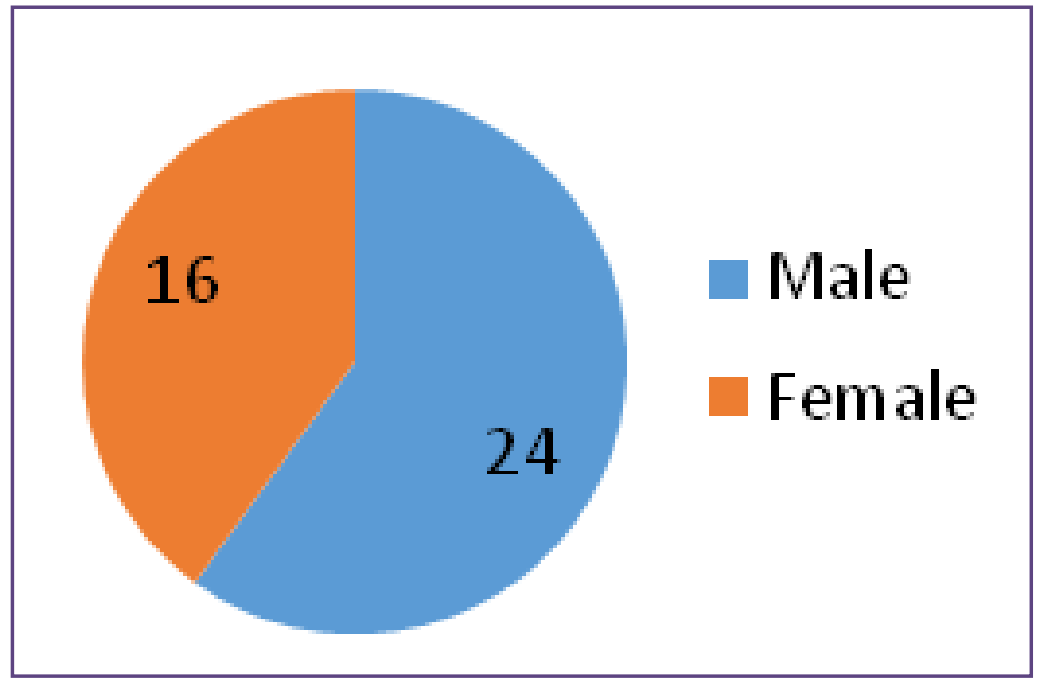

Fig. 2: Sex Distribution of patients in the study.

\section{Discussion}

Mode of transmission of HIV infection in ART recipients

The most common mode of transmission of HIV was heterosexual (75.56\%) followed by homosexual (20\%), IV drug use (2.23\%) and blood transfusion (2.23\%).

The mean age of HIV patients on ART was 25-30 years predominantly males. As received globally all ART patients were on drug regimen

$>$ ZLN (zidovudine +lamivudine+nevirapine)

$>$ ZLE (zidovudine+ lamivudine+ efavirenz)

$>$ TLN(tenofovir+ lamivudine+ nevirapine)

Those patients not responded to primary regimen or developed toxicity; then switched over to protease inhibitor-based regimen (1 PI +2 NRTIs/ NtRTIs). ${ }^{[1]}$ Examples include:

$>\quad$ Tenofovir + Lamivudine + Lopinavir or Ritonavir.

The CD4 cell count of $\leq 200$ cell $/ \mu \mathrm{L}$ proved to be a vital marker in the management of HIV/AIDS patients. Although CD4 cell count was considered the best laboratory marker of HIV infection, it was an expensive test and not widely available because of lack of sophisticated equipment. This problem was more in resource-constrained developing countries where the majority of people infected with HIV live. ${ }^{[9]}$

A study reported that symptom free HIV patients with CD4 cell count $<400$ cells $/ \mathrm{mm}^{3}$ has a $50 \%$ risk of progression to full-blown AIDS within 3 years.

ROLE OF IL-21: The severity of infections, as well as whether a pathogen will be cleared or persists, is intimately coupled to both the innate and adaptive immune response. IL-21 can regulate these responses in multiple ways. Although the role of IL-21 during immunity to infections is not currently extensively documented, a number of reports do implicate intriguing roles for this cytokine in dictating immunity to infections. The intrinsic ability of IL-21 to promote the longevity of B cells should benchmark its role in sustained production of neutralizing antibodies by proliferating and differentiating $\mathrm{B}$ cells committed to cognate stimulating antigenic determinants. Nonetheless, immune response to identical or related antigenic insults are quite heterogeneous enlisting complex factors including ethnic and HLA elements in determining the final outcome. ${ }^{[8]}$

IL-21 plays multifaceted roles in influencing the differentiation of naive CD4 $\mathrm{T}$ cells into functionally distinct subsets. Studies of mice infected with the helminths Nippostrongylus brasiliensis, Heligmosomoides polygyrus, and Schistosomamansoni have documented the importance of IL-21 in establishing Th 2 mediated immunity. [12] Infection of IL-21R-/- mice with $N$. brasiliensis resulted in the reduction of eosinophils, lymphocytes, and macrophages in addition to lower levels of IgA and IgG1 in lung lavages. ${ }^{[14]}$ Diminished Th2 associated responses were similarly noted in the absence of IL-21 signaling following intestinal infection with $H$. polygyrus. ${ }^{[14]} \mathrm{IL}-$ 21 is not necessarily required for Th2 differentiation, but IL-21R-deficient Th2 helper CD4 T cells exhibited impaired expansion or survival, which results in a lower overall inflammatory response at local sites of infection. [16] The direct requirement for IL-21 to support developing Th2 CD4 $\mathrm{T}$ cell responses is likely responsible for the reduced responses. IL-21 has been shown to play a role in 
sustaining $\mathrm{T}$ Follicular helper ( $\mathrm{Tfh}$ ) responses, and in the context of parasitic infections, interrelationships between Th2 responses and Tfh cells have been noted.

Follicular helper cells have been shown to develop from Th2 cells following $S$. mansoni and $H$. polygyrus infection, and Tfh cells have also been shown to be a major source of IL-4. ${ }^{[14]}$ The precise roles of IL-21 in determining the relative abundance and balance of $\mathrm{Th} 2$ and $\mathrm{Tfh}$ responses as well as the nuances of their developmental connections are not yet well defined.

IL-21 plays multifaceted roles in influencing the differentiation of naive CD4 T cells into functionally distinct subsets. This cytokine's main functions are proliferation of T cells; promotes differentiation of B cells and NK cells cyto-toxicity. Plasma cells are the antibody secreting cells. Plasma cells are end cells and have a short life span of $2 \frac{1}{2}$ days. Long lived plasma cells that reside in the bone marrow constitutively produce antibody in the absence of antigen and are the cellular basis of durable humoral immunity. The generation of these long lived plasma cells depends on a series of highly orchestrated interactions between antigen-specific CD4 $\mathrm{T}$ cells and $B$ cells and the formation of germinal centres. IL-21 is a critical cytokine for the generation of virus-specific long lived plasma cells. ${ }^{[15]}$

A strong clinical correlation was also observed between levels of IL-21 and CD4 T cell. The intrinsic ability of IL21 to promote the longevity of B cells should benchmark its role in sustained production of neutralizing antibodies by proliferating and differentiating $\mathrm{B}$ cells committed to cognate stimulating antigenic determinants. Nonetheless, immune response to identical or related antigenic insults are quite heterogeneous enlisting complex factors including ethnic and HLA elements in determining the final outcome. The impact of IL-21 on antibody responses to pathogens is not well defined, but given the roles of IL-21 in promoting B cell responses and plasma cell formation, it is likely that humoral immunity to infections will be influenced by the availability and kinetics of induction of IL-21. The necessity for IL-21 in ensuring durable $\mathrm{T}$ cell immunity to acute infections appears to be subtle.

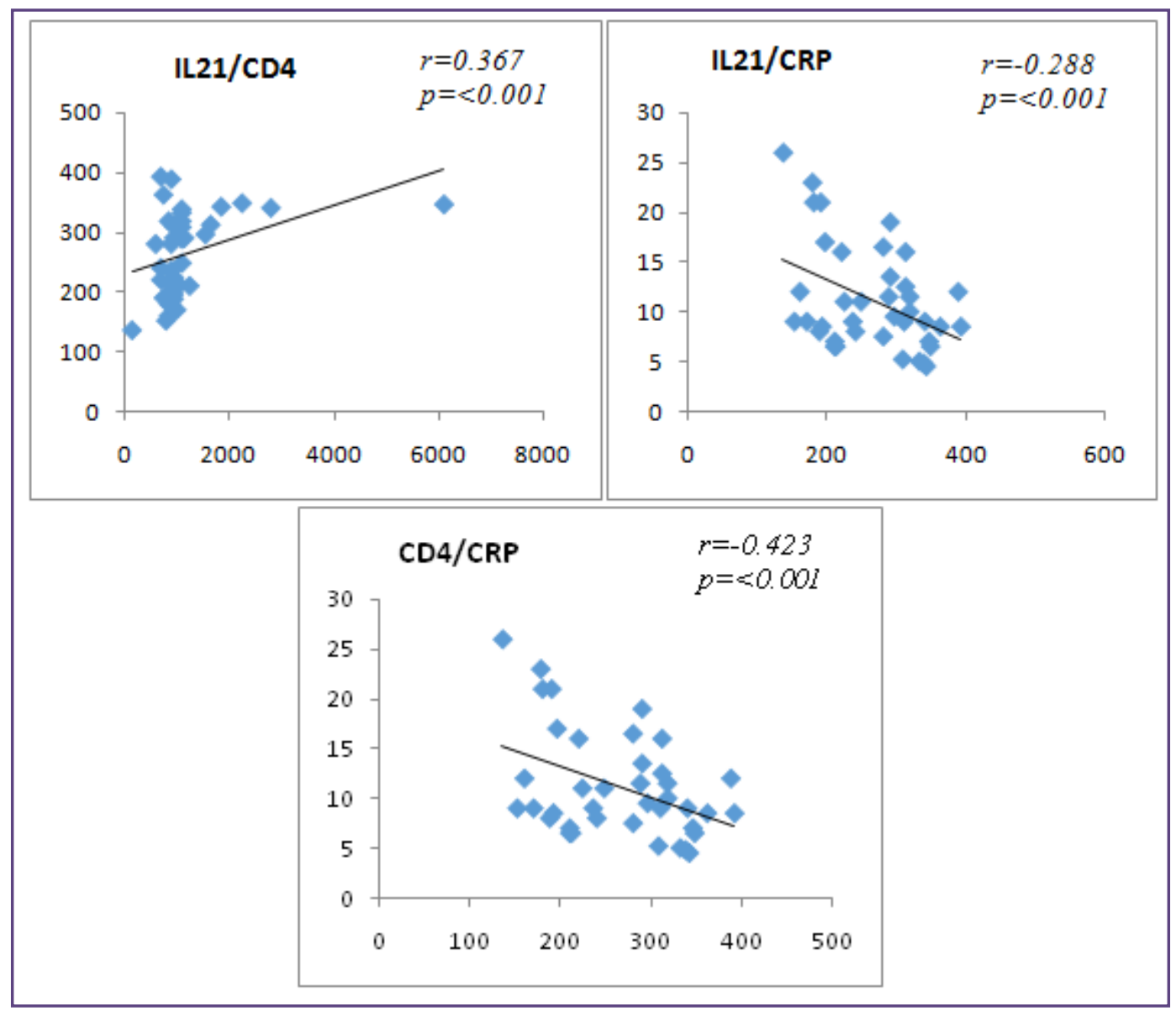

Fig. 3: Correlation between IL21/CD4, IL21/CRP and CD4/CRP. 
There is also significant negative correlation between CD 4 cell count and CRP. It shows that these two above mentioned variables are not related to each other. Their $\mathrm{p}$ value is $<0.001$ as mentioned in Figure 3. A significant positive clinical correlation was seen between the levels of IL-21 and CD4 cell counts. IL-21 levels were high in those patients whose CD4 cell count was raised. These in conjunction with other parameters could serve as important biomarkers, indicating the course of progression of the disease. Therefore, further studies with a higher sample size may be required to arrive at a statistically significant correlation.

\section{Conclusions}

This study attempts a clinical correlation with the levels of a cytokine which could help in a better understanding of the immunobiology of the disease. A significant positive clinical correlation was seen between the levels of IL21 and CD4 cell counts. IL-21 levels were high in those patients whose CD4 cell count was raised. This correlation shows that IL-21 is a potential candidate to evaluate the clinical pathophysiology of people living with HIV/ AIDS (PLHA). The correlation shows that IL-21 level is a potential indicator in determining prognosis of ART recipients.

\section{Reference}

1. Iannello A, Boulassel MR, Samarani S, Debbeche O, Tremblay C, Toma E, Routy JP, Ahmad A. Dynamics and consequences of IL-21 production in HIV-infected individuals: a longitudinal and cross-sectional study. J Immunol 2010;184(1):114-26.

2. Pallikkuth S, Parmigiani A, Pahwa S. Role of IL-21 and IL21 receptor on B cells in HIV infection. Crit Rev Immunol 2012;32(2):173-95.

3. CDC: Kaposi's sarcoma and Pneumocystis pneumonia among homosexual men-New York City and California. MMWR 1981; 30: 305-8.

4. Gallo RC, Salahuddin SZ, Popovic M et al. Frequent detection and isolation of cytopathic retroviruses (HTLV III) from patients with AIDS and at risk for AIDS. Science 1984; 224: 500-3.

5. Iannello A, Boulassel MR, Samarani S, Tremblay C, Toma E, Routy JP, et al. IL-21 enhances NK cell functions and survival in healthy and HIV-infected patients with minimal stimulation of viral replication. J Leukoc Biol 2010;87(5):857-67.

6. Kapil A, Bhaskaran CS. Human immunodeficiency virus: AIDS. In: Kapil A, Bhaskaran CS, editors. Textbook of Microbiology, 9th ed. Hyderabad: Universities Press (India) Pvt Ltd.; 2013:570-588.

7. Iannello A, Boulassel MR, Samarani S, Debbeche O, Tremblay C, Toma E, et al. Dynamics and consequences of IL-21 production in HIV-infected individuals: a longitudinal and cross-sectional study. J Immunol 2010;184(1):114-26.

8. Zheng L, Diallo M, Chen X, Zheng Y, He Y, Zhou H, et al. IL-21 level in Chinese HIV infected individuals and its dynamics undergoing HAART. Zhong Nan Da Xue Xue Bao Yi Xue Ban 2011;36(11):1059-64.

9. Williams LD, Bansal A, Sabbaj S, Heath SL, Song W, Tang $\mathrm{J}$, et al. Interleukin-21-producing HIV-1-specific CD8 T cells are preferentially seen in elite controllers. J Virol 2011;85(5):2316-24.

10. Yue FY, Lo C, Sakhdari A, Lee EY, Kovacs CM, Benko E, et al. HIV-specific IL-21 producing CD4+ T cells are induced in acute and chronic progressive HIV infection and are associated with relative viral control. J Immunol 2010;185(1):498-506.

11. Guidelines for HIV testing. NACO, Ministry of Health \& Family Welfare, 2012.

12. UNAIDS Report on the Global AID Epidemic, 2013.

13. WHO. Priority interventions, HIV/AIDS Prevention treatment and care in the health sector, August 208, WHO HIV/AIDS Department, 2008.

14. UNAIDS. Global Report, UNAIDS Report on the Global Epidemic, 2012.

15. Park K. Park's Textbook of Preventive and Social Medicine, 22nd ed., 2014.

16. US Global Health Policy. The Global HIV/AIDS Epidemic, Fact Sheet, July 2012.

*Corresponding author:

Dr. Manoj Kumar Meena, H. No. 3150-A/229, Chander Nagar, Tri Nagar, Delhi-110035, India

Phone: +91 9953547019

Email: drmanojmeena005@gmail.com

Financial or other Competing Interests: None. 